\title{
Slant shear strength of fibre reinforced polyvinyl acetate (PVA) modified mortar
}

\author{
Stefanus Kristiawan ${ }^{1, *}$, Bambang Santosa ${ }^{1}$, Edy Purwanto $^{1}$, and Rachmad A. Caesar ${ }^{2}$ \\ ${ }^{1}$ SMARTCrete Research Group, Civil Engineering Department, Universitas Sebelas Maret, Jl. Ir. \\ Sutami No. 36 A, Surakarta 57126, Indonesia \\ ${ }^{2}$ Civil Engineering Department, Universitas Sebelas Maret, J1. Ir. Sutami No. 36 A, Surakarta 57126, \\ Indonesia
}

\begin{abstract}
Strengthening of reinforced concrete elements can be carried out using a variety of materials and techniques. One of such materials is textile reinforced concrete (TRC). This material consists of a matrix, usually made of mortar, and textile as reinforcement. This study aims to produce mortar that meets the characteristic of a TRC matrix with respect to an adequate bond strength. The type of mortar developed in this study was fibre reinforced polyvinyl acetate (PVA) modified mortar. The bond strength of this material to the parent concrete was tested by the slant shear method. The results indicate that the amount of PVA content affects the magnitude of the bond strength. The higher the PVA content, the higher the bond strength. The results also confirm that the relationship between the bond strengths and their corresponding compressive strengths tends to be linear.
\end{abstract}

\section{Introduction}

Sustainability is a major issue affecting the design and performance requirements of concrete [1]. The issue challenges the concrete industry to create concrete with a minimum exploitation of non-renewable natural resources, a minimum impact to environment, costefficient production, etc. The creation of durable concrete can be a key factor in meeting such challenges. Durable concrete promotes a longer service life of the constructed infrastructures with minimum required maintenance throughout their lifespan. This means durable concrete can reduce the consumption of natural resources.

Concrete in combination with steel reinforcement is widely utilised as a structural material. This material is considered to be a durable material. Under normal conditions, it is expected that reinforced concrete (RC) structures can have a service life of at least 50 years [2]. However, there may be such situations where deterioration of RC structures could occur at a faster rate, resulting in a service life of less than 20 years [3]. These situations challenge engineers to seek innovative solutions to prevent deterioration and offer methods to extend the service life of the deteriorated RC structures. Accordingly, many materials have been developed specifically to protect, repair and rehabilitate this deterioration issue.

\footnotetext{
* Corresponding author: s.a.kristiawan@ft.uns.ac.id
} 
These include surface protection in the form of hydrophobic impregnation, impregnation or coating [4]; and various repair products such as cementitious-based repair mortar, polymer modified mortar, polymer mortar, fibre reinforced mortar, and engineering cementitious composite [5-7]. There may be also necessary actions to strengthen the existing RC structures in order to suit the new requirements of loadings. In such cases, the following materials could for example be chosen: fibre reinforced polymer (FRP), carbon fibre reinforced polymer (CRFP), and textile reinforced concrete (TRC) [8-10].

TRC consists of concrete having fine graded aggregates or mortar reinforced with textile. The binder content for making the mortar is relatively high, i.e. about $40-50 \%$ by volume of the mortar [11]. The high binder content combined with the right proportion of fine graded aggregates and water can promote fresh mortar with the ability to flow and conceal the textile reinforcement. The bond between the textile reinforcement and the surrounding mortar is the result of the progress of mortar hardening. In a hardened state, the embedded textile reinforcement is expected to have a sufficient bond strength and so can act to reinforce the mortar when the TRC is under loading.

TRC has been applied to strengthen various RC elements. Schladitz et al. [12] used TRC to increase the bending capacity of a RC slab. Verbruggen et al. [13] investigated external reinforcements of beams with TRC and a carbon fibre reinforced polymer (CFRP). They showed the similarity of the cracking behaviour between a TRC reinforced-beam and CFRP reinforced-beam. Elsanadedy et al. [14] indicated that strengthening an RC beam with textile reinforced mortar (TRM) is more effective in terms of ductility performance compared to its fibre reinforced polymer (FRP) counterpart, even though it is less effective in terms of enhancing the flexural strength. Larbi et al. [15] applied TRC in combination with glass/carbon rods (hybrid strengthening) to enhance the ultimate and service performance of an RC beam under flexural loading. Meanwhile, Contamine et al. [16] assessed the mechanical performance of TRC in the shear repair of an RC beam. They showed that TRC has a comparable performance to that of shear strengthening of an RC beam using CFRP. Ombres [17] applied a type of TRC, i.e. PBO (Polypara-phenylenebenzo-bisthiazole) fibre meshes embedded into an inorganic stabilized cementitious matrix (Fibre Reinforced Cementitious Mortar, FRCM), as a concrete confinement. He showed that a significant increase both in peak strength and axial strain was obtained by tests on the confined specimens.

The effectiveness of TRC as a strengthening material is determined, among other properties, by the ability of this material to develop a bond to the parent concrete. Insufficient bond strength tends to provoke separation between the TRC and parent concrete. A sufficient bond strength will guarantee that the two materials (the TRC and parent concrete) can act as a composite system. A variety of factors affect the development of the bond between the TRC and parent concrete. For example, close contact between the $\mathrm{TRC}$ and parent concrete is essential. Any entrapped air voids at the bond interface can generate stress concentrations that may lead to separation [18]. Close contact of the two materials also increases the area of the interface bond. Meanwhile, cleaning the surface of the substrate concrete prior to the application of the repair layer can remove undesirable dirt at the bond interface which hinder the development of the bond between the layers of TRC and substrate concrete. A further increase of the interface bond can be achieved by other surface preparations methods. Surface roughness of the substrate concrete created by using wire-brushing, sand-blasting, and chipping with a light jackhammer can significantly increase the bond strength. The same is true when the surface is roughened by using acid etching, grooving, grooved-wire brushing and grooved-acid etching. Meanwhile, conducting pre-wetting, adding cement slurry or adding polymer-based coating on the surface of substrate concrete do not influence the bond strength [19-21]. 
Apart from the above physical/mechanical factors, the bond strength development of TRC to the substrate concrete is essentially influenced by the composition of the TRC matrix, especially the cement. Given that the TRC matrix is a cement-based material, the adhesion to the substrate concrete is a consequence of the cement hydration process. The hydrated cement will develop a bond to the solid components in contact with it. Therefore, any admixtures used to modify the cement will affect the bond strength development. In this research, a type of polymer, polyvinyl acetate (PVA), is used to modify the binding property of the TRC matrix (mortar). It has been shown by previous researchers [22] that PVA can enhance the bond strength of mortar when tested by the pull-off method. For the current investigation, the influence of the PVA content on the bond strength between the mortar and substrate concrete will be studied by using the slant shear test method. Furthermore, the type of mortar investigated in this research is fibre reinforced mortar, in which cantala short-fibres are dispersed randomly into the PVA-mortar mixes. The use of fibre is essential to prevent cracking of the mortar layer near the interface associated with differential shrinkage. The presence of cracks can consequently decrease the bond between the mortar layer and the substrate concrete [23, 24]. The success of this investigation will open new opportunities to develop TRC matrixes meeting the minimum bond strength requirement.

\section{Materials and method}

\subsection{Materials}

The relative proportion of the constituents for producing the TRC matrix (fibre reinforced polyvinyl acetate (PVA)-modified mortar) is presented in Table 1. The ratio of cement (C) to fine graded aggregate (FGA) was set at 1:2. The FGA was that of passing through a mesh of $1.18 \mathrm{~mm}$ but retaining a mesh of $0.15 \mathrm{~mm}$. The PVA contents were varied in a range of $15-30 \%$ by the weight of C. The PVA was in liquid form and contained $50 \%$ water. This water was taken into account to reduce the water requirement in order to maintain a constant water-to-cement ratio of 0.35 for all mixes. For example, originally the total water (TW) requirement for all mixes was $0.35 \mathrm{~kg}$ as shown in Table 1 . This amount was then reduced by the water contained in the PVA. The corrected water $(\mathrm{CW})$ for each mix after this subtraction is shown in Table 1. The amount of $\mathrm{CW}$ was further reduced by the amount of accelerator (Acc) since the manufacture of this admixture recommends the use of admixture without additional water to produce rapid hardening mortar. Hence, in this investigation the liquid form of the Acc was considered to be acting similar to water in addition to its role to accelerate the hardening of the mortar. The Acc was added into the mix at $45 \%$ of the weight of the $\mathrm{CW}$ and the amount was converted into $\mathrm{kg}$ as shown in Table 1. The final free water requirement (W) of each mix was obtained by subtracting the $\mathrm{CW}$ with the Acc. In the meantime, the superplasticizer (Sp) was added at a fixed amount of $1 \%$ of the weight of the cement, whereas the amount of cantala short fibre (Csf) was set at $0.41 \%$ volume fraction of the mortar.

Table 1. Proportion of fibre reinforced polymer mortars investigated in this study.

\begin{tabular}{|c|c|c|c|c|c|c|c|c|c|}
\hline $\begin{array}{c}\text { Specimen } \\
\text { ID }\end{array}$ & $\begin{array}{c}\text { C } \\
(\mathbf{k g})\end{array}$ & $\begin{array}{c}\text { FGA } \\
(\mathbf{k g})\end{array}$ & $\begin{array}{c}\text { TW } \\
(\mathbf{k g})\end{array}$ & $\begin{array}{c}\text { PVA } \\
(\mathbf{\%})^{*}\end{array}$ & $\begin{array}{c}\mathbf{C W} \\
(\mathbf{k g})\end{array}$ & $\begin{array}{c}\text { Acc } \\
(\mathbf{k g})\end{array}$ & $\begin{array}{c}\mathbf{W} \\
(\mathbf{k g})\end{array}$ & $\begin{array}{c}\text { Sp } \\
(\mathbf{\%})^{*}\end{array}$ & $\begin{array}{c}\text { Csf } \\
(\mathbf{\%}) * *\end{array}$ \\
\hline PVA-15 & 1 & 2 & 0.35 & 15 & 0.275 & 0.12375 & 0.15125 & 1 & 0.41 \\
\hline PVA-20 & 1 & 2 & 0.35 & 20 & 0.250 & 0.11250 & 0.13750 & 1 & 0.41 \\
\hline PVA-25 & 1 & 2 & 0.35 & 25 & 0.225 & 0.10125 & 0.12375 & 1 & 0.41 \\
\hline PVA-30 & 1 & 2 & 0.35 & 30 & 0.200 & 0.09000 & 0.11000 & 1 & 0.41 \\
\hline
\end{tabular}

*by weight of cement; ** by weight of mortar 
The cantala fibre, seen in Figure 1, used in this investigation was extracted from Agave cantala leaves. The fibres were produced by a home industry in Kulon Progo, Yogyakarta, Indonesia and the final product of the fibres had an average diameter of about $140 \mu \mathrm{m}$. For the purpose of this study, the fibres were cut into short-fibres with an average length of about $10 \mathrm{~mm}$.
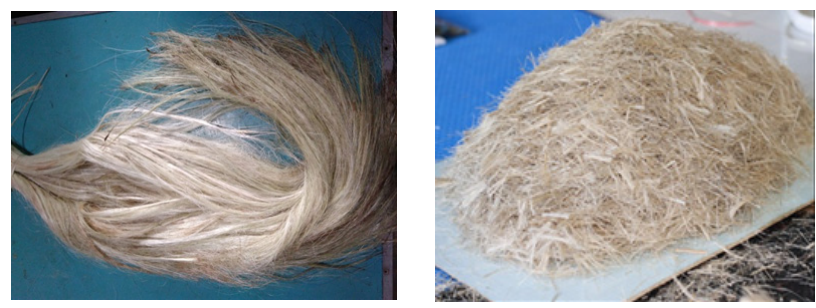

Fig. 1. Cantala fibres (left) were cut into short-fibres (right).

\subsection{Method}

The bond strength of the matrix of the TRC (i.e. fibre reinforced PVA modified mortar) to the substrate concrete was determined by the slant shear test method in accordance with BS 6319: Part 4 [25]. Figure 2 illustrates the composite prism specimen made from substrate concrete and fibre reinforced PVA modified mortar for the purpose of determining the slant shear strength. The size of the slant shear specimens was 55x100x250 mm. The composite prisms were produced with a bond line at $30^{\circ}$ to the vertical. The composite prisms were produced by the following sequence: First, substrate concrete was cast to form a half of the prism with a bond line at $30^{\circ}$ to the vertical. After 28 days, fibre reinforced PVA modified mortar was cast on the remaining half of the prism to form a composite prism. No preparation on the bond plane of the substrate concrete was made before casting the layer of fibre reinforced PVA modified mortar. Once the layer of fibre reinforced PVA modified mortar was cast, the specimens were left at room temperature until the day of testing. The slant shear test was carried out at 3 and 28 days after casting of the fibre reinforced PVA modified mortar. The slant shear strengths were calculated using Equation 1:

$$
f_{c r}^{\prime}=\frac{P}{A} \cos \alpha \cdot \sin \alpha
$$

where $f_{c r}^{\prime}, P, A, \alpha$ is slant shear strength, maximum applied load, horizontal area of specimen and bond line $\left(30^{\circ}\right)$, respectively (see Figure 2 ).
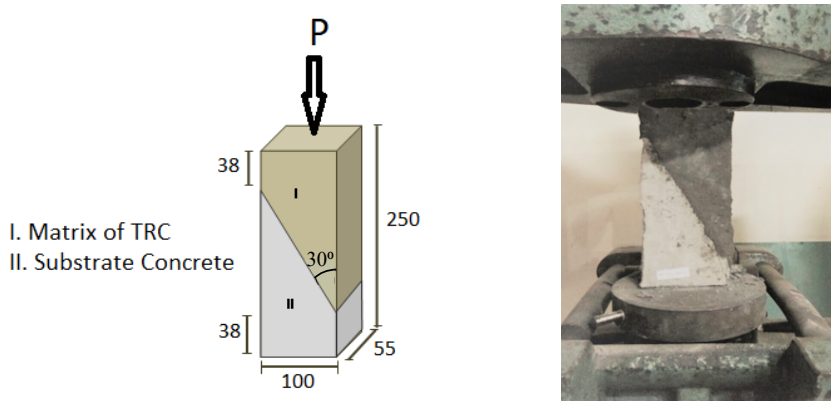

Fig. 2. Composite prism specimen for determining slant shear test under compressive loading. 
In addition to the slant shear test, cube specimens of 50x50x50 mm were prepared to determine the compressive strength of the fibre reinforced PVA modified mortars. The compressive strength test was carried out following the ASTM C 579-01 [26]. The compressive strength was determined at 3 and 28 days of age. Meanwhile, concrete with an average compressive strength (at 28 days) of $24 \mathrm{MPa}$ was prepared to represent the substrate concrete. This concrete was proportioned following the Indonesian Code (SNI 032834-2000) [27].

\section{Results and discussion}

\subsection{Slant shear strength}

The slant shear strength of the fibre reinforced PVA modified mortars is presented in Figure 3. As expected, the 28-d slant shear strength is higher than the 3-d slant shear strength. This characteristic is true for all mixes of fibre reinforced PVA modified mortars. The 3-d slant shear strength represents only about $33-50 \%$ of the 28 -d slant shear strength. It also clearly shows that the slant shear strength is increased with respect to the increase of PVA content. The improvement of bonding with the PVA content could be a result of diffusion of polymer matrixes that are mutually intertwined at the interface [22]. Furthermore, the formation of PVA films may occur at the bond plane that close the entrapped air voids on this interface and bridge the two composite components.

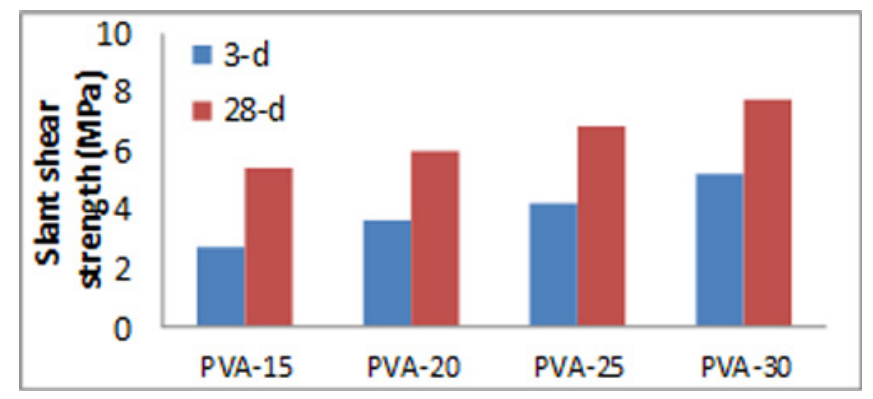

Fig. 3. Slant shear strength of the fibre reinforced PVA modified mortars.

The 3-d slant shear strength of the fibre reinforced PVA modified mortar will rise up to $91 \%$ when the PVA content is increased from $15 \%$ to $30 \%$. If measured at $28-\mathrm{d}$, the increase of the slant shear strength will be around $43 \%$. This significant difference of the slant shear strength increase with respect to the age of fibre reinforced PVA mortar may be related to the balance contribution of the bond due to the hydration progress and PVA. At an early age, the cement-based material is still in the process of developing a bond to the substrate concrete in line with the progress of hydration. Hence, the contribution of the PVA to improve the bonding is significant to the overall development of bond strength. On the other hand, at later ages the hydration is nearly completed and so the ultimate bond strength due to hydration is practically attained. Consequently, the relative contribution of PVA on the bond strength is less significant to the overall development of the bond strength.

The slant shear test method (see Figure 2) suggests that a variety of failure modes can be expected. The first failure mode is a failure of the TRC matrix (fibre reinforced PVA modified mortar). This type of failure can occur when the fibre reinforced PVA modified mortar has not developed sufficient compressive strength to resist the applied compressive load. The second type of failure mode is that of interface failure. In this mode, the two 
composite components are separated. This type of failure mode can be expected when the fibre reinforced PVA modified mortar has not developed an adequate bond to the substrate concrete while its compressive strength is sufficient to withstand the applied compressive load. These two types of failure mode are commonly observed at an early age when the mortar component is still developing its strength. For the current investigation, most of the failure modes occurring at early ages fall within interface failure (see Table 2). The third type of failure mode is that of substrate concrete failure in which the compressive strength of the concrete is the weakest strength to resist the applied load. The last type of failure mode is that of double failure where the failure is a combination of at least two modes of failure as mentioned above. This last type of failure mode can be expected when the mortar component of the specimen has developed sufficient compressive strength comparable to the substrate concrete and at the same time has attained an adequate bond to the substrate concrete. Most of the failure modes occurring at later ages fall within the double failure type (see Table 2). Figure 4 shows the types of failure modes observed in this current investigation. BS EN1504-4:2004 [5] recommends that the slant shear test shall result in fracture in the substrate concrete. The 28-d failure modes of the fibre reinforced PVA modified mortar investigated in this study indicate that fracture in the substrate concrete (having a compressive strength of $24 \mathrm{MPa}$ ) did occur.

Table 2. Failure modes of the slant shear test.

\begin{tabular}{|c|c|c|c|}
\hline Age & Spec. ID & Spec. \# & Failure mode \\
\hline \multirow{12}{*}{$3-d$} & \multirow{3}{*}{ PVA-15 } & 1 & interface failure \\
\hline & & 2 & interface failure \\
\hline & & 3 & mortar failure \\
\hline & \multirow{3}{*}{ PVA-20 } & 1 & interface failure \\
\hline & & 2 & interface failure \\
\hline & & 3 & interface failure \\
\hline & \multirow{3}{*}{ PVA-25 } & 1 & interface failure \\
\hline & & 2 & interface failure \\
\hline & & 3 & interface failure \\
\hline & \multirow{3}{*}{ PVA-30 } & 1 & interface failure \\
\hline & & 2 & interface failure \\
\hline & & 3 & concrete, mortar \& interface failure \\
\hline \multirow{12}{*}{$28-d$} & \multirow{3}{*}{ PVA-15 } & 1 & concrete, mortar \& interface failure \\
\hline & & 2 & concrete, mortar \& interface failure \\
\hline & & 3 & concrete, mortar \& interface failure \\
\hline & \multirow{3}{*}{ PVA-20 } & 1 & concrete, mortar \& interface failure \\
\hline & & 2 & concrete, mortar \& interface failure \\
\hline & & 3 & concrete, mortar \& interface failure \\
\hline & \multirow{3}{*}{ PVA-25 } & 1 & concrete, mortar \& interface failure \\
\hline & & 2 & interface failure \\
\hline & & 3 & concrete, mortar \& interface failure \\
\hline & \multirow{3}{*}{ PVA-30 } & 1 & concrete, mortar \& interface failure \\
\hline & & 2 & concrete, mortar \& interface failure \\
\hline & & 3 & concrete, mortar \& interface failure \\
\hline
\end{tabular}




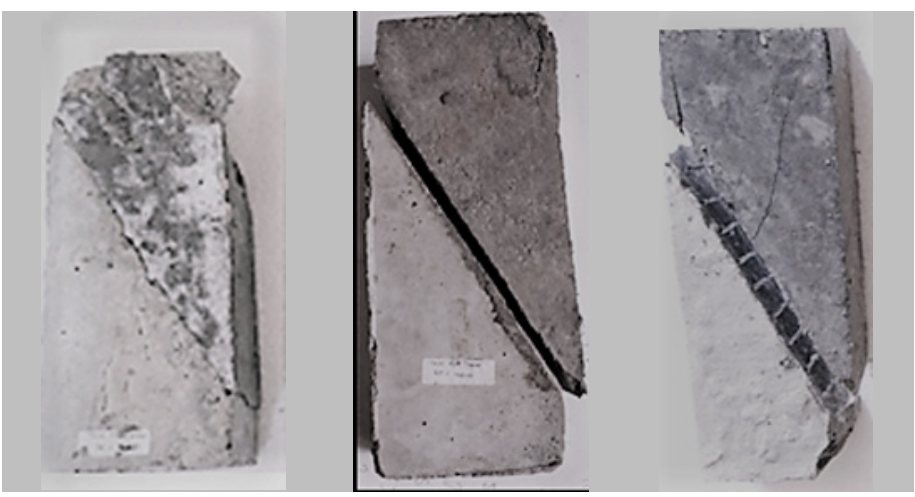

Fig. 4. Failure modes observed in this investigation: mortar failure (left), interface failure (middle), and double failure (right).

\subsection{Correlation of slant shear strength and compressive strength}

The compressive strength of the fibre reinforced PVA modified mortars is presented in Figure 5. It seems that the compressive strength of these mortars has a similar trend to their slant shear strength. An increase in the PVA content will increase the compressive strength in a similar manner to that of the slant shear strength. For this reason, a correlation between the two strengths has been established as shown in Figure 6. Based on this figure, it is found that the slant shear strength is about $24 \%$ of the compressive strength.

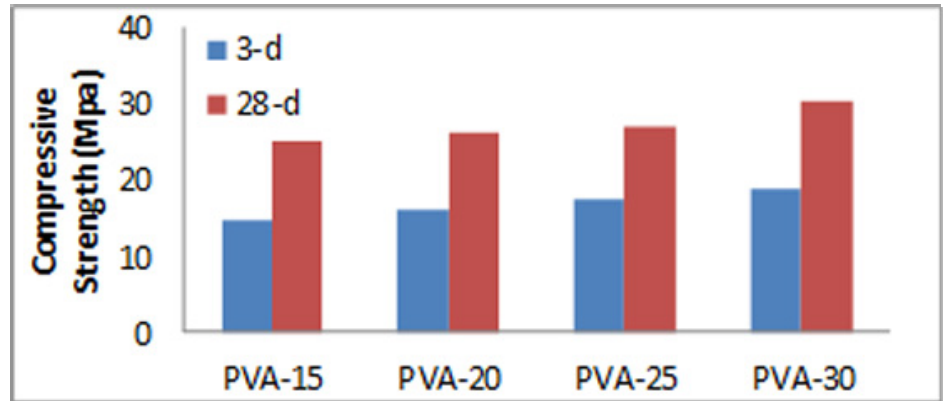

Fig. 5. Compressive strength of fibre reinforced PVA modified mortar.

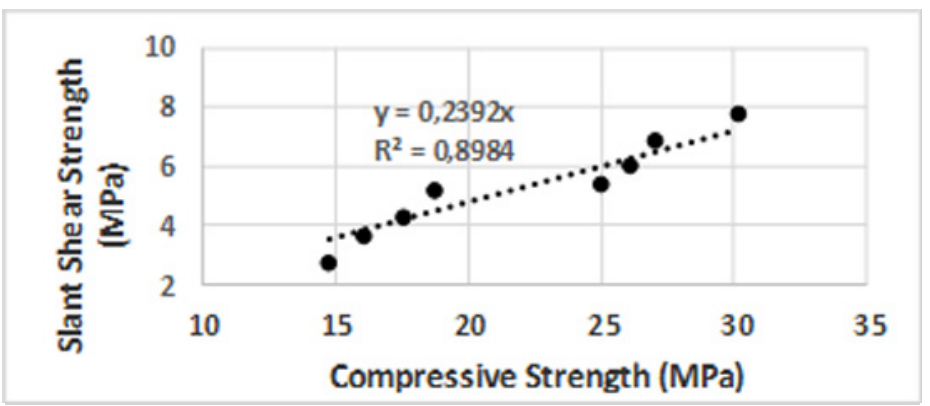

Fig. 6. Correlation between slant shear strength and compressive strength of fibre reinforced PVA modified mortar. 


\section{Conclusions}

This study shows that the amount of PVA affects the bond strength of the fibre reinforced PVA modified mortar to the substrate concrete. The higher the amount of the PVA content, the higher the bond strength. It is also noticed that the effect of PVA is weightier at early ages when the contribution of the bond due to the cement hydration has not yet attained its ultimate value.

At an early age, the failure modes of the slant shear test are dominated by interface failure. It is likely that at early ages the fibre reinforced PVA modified mortar has not developed a sufficient bond to the substrate concrete. At later ages, however, a maximum cement hydration of the fibre reinforced PVA modified mortar is practically attained and the mortar has developed a sufficient bond to the substrate concrete. Consequently, the failure modes of the slant shear test at later ages were dominated by double failure.

This investigation shows that the 3-d slant shear strength of the fibre reinforced PVA modified mortar to the substrate concrete only represents about $33-50 \%$ of the 28 -d slant shear strength. It also confirmed that a linear relationship (by a factor of 0.24 ) can be established to correlate between the slant shear strength and the compressive strength.

This research has been made possible due to the financial support by the University of Sebelas Maret (contract No. 543/UN27.21/PP/2018).

\section{References}

1. H.S. Mueller, M. Haist. J.S. Moffatt, M. Vogel, Proc. Eng, 171, 22-32, (2017)

2. EN 1990:2002 Eurocode - Basis of structural design (European Committee for Standardization, Brussels, Belgium), (2002)

3. P.K. Mehta, R.W. Burrows, Indian Concr. J., 23, 57-63, (2001)

4. BS EN 1504-3: 2005 Products and systems for the protection and repair of concrete structures - Definitions, requirements, quality control and evaluation of conformity Part 3: Structural and non-structural repair (British Standard Institution, 389 Chiswick High Road, London W4 4AL), (2005)

5. BS EN 1504-4: 2005 Products and systems for the protection and repair of concrete structures - Definitions, requirements, quality control and evaluation of conformity Part 4: Structural bonding (British Standard Institution, 389 Chiswick High Road, London W4 4AL), (2005)

6. A. Ghazy, M. T. Bassuoni, E. Maguire., M. O’Loan, Fib. 4, 6, (2016)

7. V.C. Lia, H. Horiib, P. Kabeleb, T. Kandac, Y.M. Lim, Eng. Frac. Mech. 65, 317-334, (2000)

8. T.M. Pham, M.N.S. Hadi, Constr. Build. Mater. 69, 83-90, (2014)

9. A. Li, C. Diagana, Y. Delmas, Eng. Struct. 23, 1212-1220, (2001)

10. M. Tsesarsky, A. Peled, A. Katz, I. Anteby, Constr. Build. Mater. 44, 514-523, (2013)

11. M. Mobasher, Mechanics of fiber and textile reinforced cement composites (CRC Press, Florida), (2012)

12. F. Schladitz, M. Frenzel, D. Ehlig, M. Curbach, Eng. Struct. 40, 317-326, (2012)

13. S. Verbruggen, T. Tysmans, J. Wastiels, Eng. Struct. 77, 49-56, (2014)

14. H.M. Elsanadedy, T.H. Almusallam, S.H. Alsayed, Y.A. Al-Salloum, Compos. Struct. 97, 40-55, (2013)

15. A.S. Larbi, R. Contamine, P. Hamelin, Eng. Struct. 45, 12-20, (2012) 
16. R. Contamine, A. S. Larbi, P. Hamelin, Eng. Struct. 46, 447-458, (2013)

17. L. Ombres, Compos. Struct. 94, 143-155, (2011)

18. Y. Pan, Bond strength of patch repairs: An evaluation of test methods and the influence of workmanship and environment (Doctoral Thesis, the Loughborough University of Technology), (2005)

19. E.N.B.S. Julio, F.A.B. Branco, V.D. Silva, Constr. Build. Mater. 18, 675-681, (2004)

20. M. Mohammadi, R.M. Moghtadaei, N.A. Samani, Constr. Build. Mater. 51, 141-150, (2014)

21. R. Mirmoghtadaei, M. Mohammadi, N.A. Samani, S. Mousavi, Constr. Build. Mater. 80, 76-83, (2015)

22. J.J. Assaad, Constr. Build. Mater. 163, 139-148, (2018)

23. C. Zanotti, N. Banthia, G. Plizzari, Cem. Concr. Res. 63, 117-126, (2014)

24. C. Zanotti, G. Rostagno, B. Tingley, Constr. Build. Mater. 160, 775-785, (2018)

25. BS 6319-4: 1984 Testing of resin and polymer/cement compositions for use in construction. Method for measurement of bond strength (slant shear method) (British Standard Institution, 389 Chiswick High Road, London W4 4AL), (1984)

26. ASTM C579-01 Standard test methods for compressive strength of chemical-resistant mortars, grouts, monolithic surfacings, and polymer concretes (ASTM International, West Conshohocken, PA), (2012)

27. SNI 03-2834-2000 Tata cara pembuatan rencana campuran beton normal (Badan Standarisasi Nasional, Jl. MH. Thamrin No. 8, Kebon Sirih $(406,85$ km), Daerah Khusus Ibukota Jakarta 10340), (2000) 